\title{
PAPER
}

Cite this: DOI: $10.1039 / c 7 n j 00733 g$

\section{Twisted intramolecular charge transfer in a carbazole-based chromophore: the stable [ $(4-\mathrm{N}-$ carbazolyl)-2,3,5,6-tetrachlorophenyl]bis(2,3,5,6- tetrachlorophenyl)methyl radical $\dagger$}

Received 3rd March 2017, Accepted 3rd July 2017

DOI: $10.1039 / c 7 n j 00733 g$

rsc.li/njc

\author{
Alejandra Gilabert, ${ }^{a}$ Lluís Fajarí, ${ }^{a}$ Ignasi Sirés, ${ }^{b}$ Marta Reig, ${ }^{c}$ Enric Brillas, ${ }^{b}$ \\ Dolores Velasco, \\ Josep M. Anglada (D) and Luis Juliá
}

A neutral stable organic radical adduct, 1, composed of a donor-acceptor dyad is reported. The electron-donor part is the carbazolyl ring directly linked to the electron-acceptor polychlorotriphenylmethyl radical through the para position of a phenyl ring. In the synthetic procedure a $\mathrm{C}\left(\mathrm{sp}^{2}\right)-\mathrm{H}$ bond is transformed into a $\mathrm{C}\left(\mathrm{sp}^{2}\right)-\mathrm{N}$ bond through the radical-radical cross-coupling process. Theoretical calculations predict that the tetrachlorophenyl bridge moiety lies perpendicular to the carbazolyl group to minimize the repulsion with the chlorine atoms in the ortho position. The electron paramagnetic resonance (epr) spectrum of 1 exhibits a small coupling of the electronic spin with the carbazolyl nitrogen $(0.32 \mathrm{G})$, the spin density being mainly located in the central $\mathrm{sp}^{2}$ carbon atom (30.22 G). The radical adduct presents a charge transfer band $(\lambda=598-640 \mathrm{~nm})$ showing a hypsochromic shift with solvent polarity. In DMF solution, 1 exhibits a new weak band $(\lambda=493 \mathrm{~nm}$ ) which is tentatively attributed to a zwitterionic structure of the molecule resulting from a net electron transfer from the nitrogen to the central $\mathrm{sp}^{2}$ carbon atom. Cyclic voltammetry of 1 confirms the amphoteric character of the molecule. Computed values of ionization potential (IP) and electron affinity (EA) are in good agreement with the experimental values.

\section{Introduction}

Many carbazole derivatives have been the source of great interest for materials scientists due to their intrinsic physical and redox properties. ${ }^{1}$ In particular, they exhibit relatively intense luminescence ${ }^{2}$ and have been intensively studied as charge carrier transporting materials in the field of organic light-emitting diodes (OLEDs). ${ }^{3}$ However, the poor nucleophilic power of the nonbonding electron pair on nitrogen has made its incorporation into aromatic systems by classical methods difficult, requiring severe reaction conditions. Several synthetic strategies to obtain $N$-aryl derivatives of carbazole by using $\mathrm{Cu}$ / bronze $^{4}$ or palladium catalysts ${ }^{5}$ have been reported. Thus,

\footnotetext{
${ }^{a}$ Departament de Quimica Biològica i Modelització Molecular, Institut de Química Avançada de Catalunya (CSIC), Jordi Girona 18-26, 08034 Barcelona, Spain. E-mail: ljbmoh@cid.csic.es

$50{ }^{b}$ Laboratori d'Electroquimica dels Materials i del Medi Ambient, Departament de Química Física, Universitat de Barcelona, Martí Franquès 1-11, 08028 Barcelona, Spain

Departament de Quimica Inorgànica i Orgànica, Secció Química Orgànica, Institut de Nanociència i Nanotecnologia (IN $\left.{ }^{2} U B\right)$, Universitat de Barcelona, Martí Franquès 1-11, 08028 Barcelona, Spain

$55 \dagger$ Electronic supplementary information (ESI) available: Fig. S1-S9 and Tables S1 and S2. See DOI: 10.1039/c7nj00733g
}

different $N$-arylcarbazoles have been prepared from electronrich and electron-poor halobenzenes as electrophilic precursors. It is important to point out the high thermal and photochemical stabilities of many carbazole derivatives.

As part of our target to expand the field of new electronic devices with multiple properties, both electronic and magnetic, we have recently reported the synthesis and properties of a new carbazole derivative, the [(4- $N$-carbazolyl)-2,6-dichlorophenyl]bis(2,4,6-trichlorophenyl)methyl radical (czTTM) ${ }^{6}$ (Scheme 1), resulting from the coupling of the $\mathrm{NH}$-carbazole to the stable tris(2,4,6trichlorophenyl)-methyl (TTM) radical. In this process, a classic nucleophilic substitution is not operative in the replacement of chlorine by carbazole, but a radical mechanism supported by the trivalent carbon atom of the molecule. ${ }^{7}$

This new paramagnetic adduct presents two redox centers in the molecule, one electron-donor, the carbazole part, and one electron acceptor, the triphenylmethyl part. In this context, we have prepared new radical adducts possessing dipolar structure, with the TTM radical, as the electron-acceptor open shell half and a heterocycle, such as carbazole and indole, as the electron-donor half. ${ }^{8}$ All of them have shown significant thermal stabilities. Furthermore, the presence of the carbazolyl fragment with TTM has been revealed as an efficient strategy to obtain ambipolar transport properties. ${ }^{9}$ 


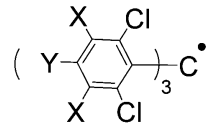

TTM: $X=\mathrm{H} ; Y=\mathrm{Cl}$ DTM: $X=\mathrm{Cl} ; Y=\mathrm{H}$

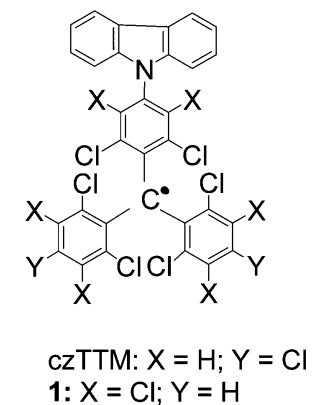

Scheme 1

Now, this paper presents the synthesis, and electronic and magnetic properties of a new radical adduct, [(4- $N$-carbazolyl)2,3,5,6-tetrachlorophenyl]bis(2,3,5,6-tetrachlorophenyl)methyl radical (1) (Scheme 1), prepared from $\mathrm{NH}$-carbazole and tris(2,3,5,6-tetrachlorophenyl)methyl radical (DTM). In this new magnetic compound, the acceptor part of the molecule, DTM, has replaced the TTM half in czTTM, with a stronger electron-acceptor power. The synthetic strategy pursued in the preparation of $\mathbf{1}$ has taken advantage of the radical mechanism operating in the synthesis of czTTM, ${ }^{6}$ incorporating a carbazolyl fragment in DTM. Thus, a $\mathrm{C}\left(\mathrm{sp}^{2}\right)-\mathrm{H}$ bond can be transformed into $\mathrm{C}\left(\mathrm{sp}^{2}\right)-\mathrm{N}$ bond. Theoretical calculations have also been carried out in order to help in rationalizing the electronic and spectral features of this radical adduct.

\section{Results and discussion}

Radical adduct 1 was obtained in a two-stage process from tris(2,3,5,6-tetrachlorophenyl)methyl radical (DTM). First, DTM was reacted with an excess of $\mathrm{NH}$-carbazole in the presence of cesium carbonate as the base in boiling anhydrous DMF, and the resulting $\mathbf{1 H}$ was treated with an aqueous solution of tetrabutylammonium hydroxide (TBAH) in THF followed by oxidation with an excess of iodine in THF (Scheme 2). In short, substitution of aromatic hydrogen by the carbazolyl ring takes place in the first process, in contrast to the more extended aromatic nucleophilic substitution of chlorine by the nucleophile. The coupling reaction between $\mathrm{NH}$-carbazole and DTM proceeds through a radical mechanism. ${ }^{7}$ Therefore, $\mathrm{NH}$ carbazole in the presence of a base is oxidized to the carbazolyl radical by electron transfer to a DTM molecule. Then the

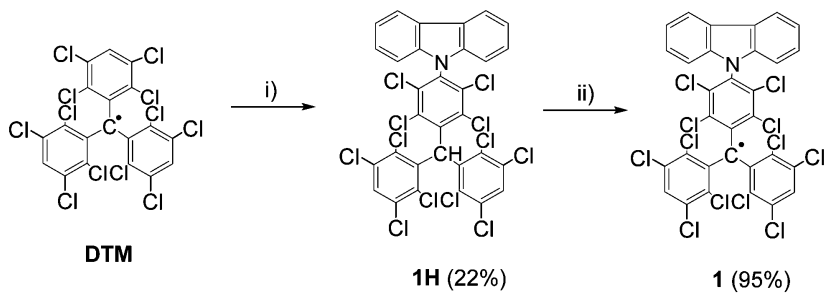

i) $\mathrm{NH}$-Carbazole, $\mathrm{Cs}_{2} \mathrm{CO}_{3}$, DMF. ii) a: $\mathrm{Bu}_{4} \mathrm{NOH}$, aqueous THF; b: $p$-chloranil

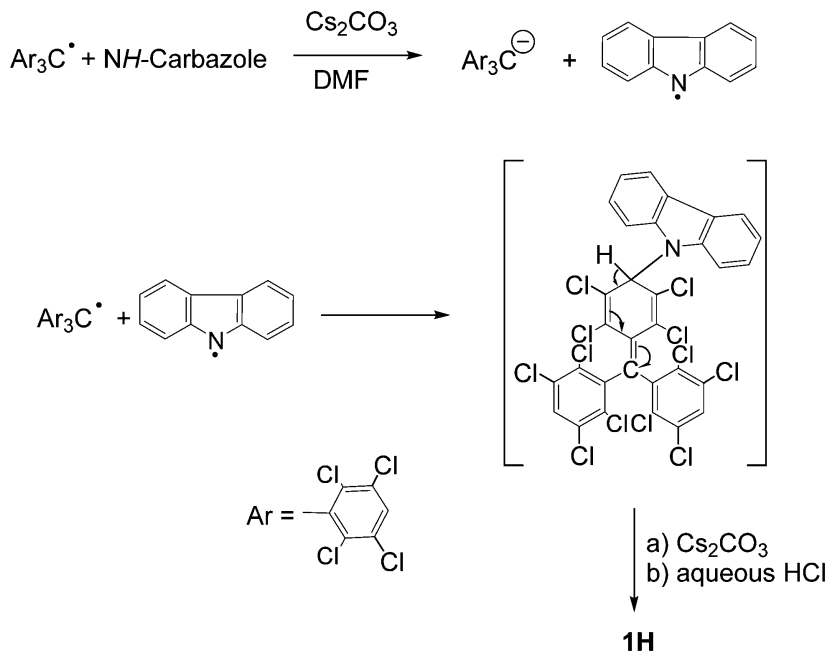

Scheme 3

generated nitrogen radical is added to another molecule of DTM to give the diamagnetic compound $\mathbf{1 H}$ as illustrated in Scheme 3. This is a nice radical-radical cross coupling reaction between a persistent carbon-radical and a reactive nitrogenradical generated "in situ" by oxidation of $\mathrm{N} H$-carbazole using the persistent radical acting as an oxidant in the presence of a base. ${ }^{10}$ The coupling takes place in the very congested DTM.

Fig. 1 displays the optimized structure of radical 1, computed at the B3LYP/6-31+G(2df,2p) level of theory and shows that this radical has a strong twisted geometry, where the

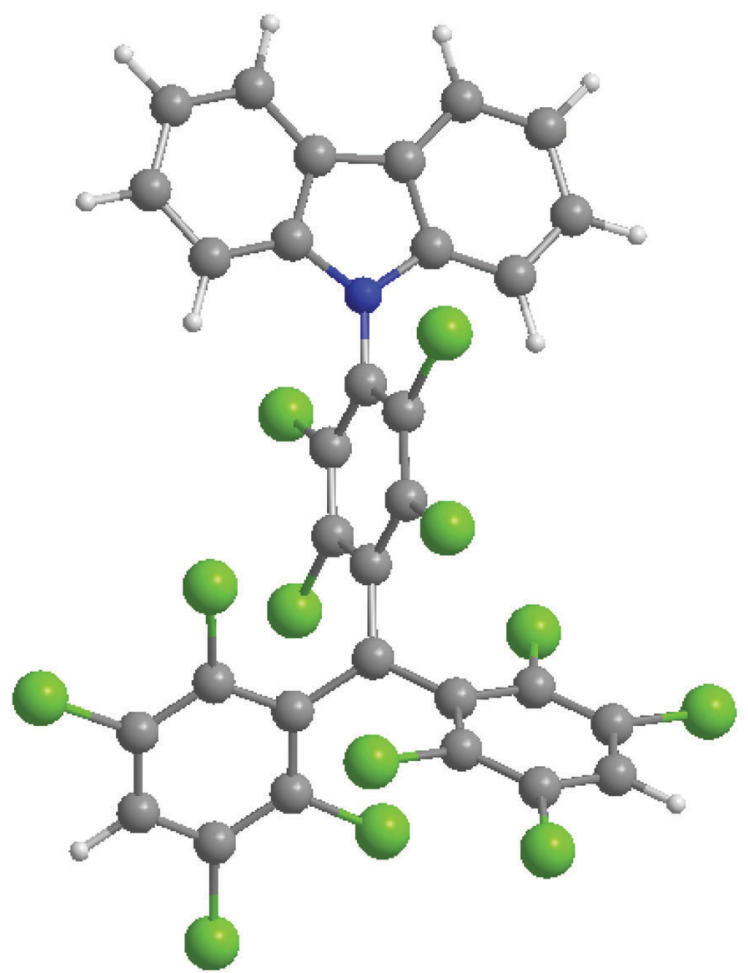

Fig. 1 Optimized structure of radical adduct 1, computed at the UB3LYP/ $6-31+G(2 d f, 2 p)$ level of theory. 
1 2,3,5,6-tetrachlorophenyl bridge moiety lies perpendicular to the carbazolyl group. At this point, it should be noted that the X-ray analysis of the czTTM molecular structure already shows an angle of $\sim 90^{\circ}$ between the 2,6-dichlorophenyl bridge and the carbazolyl groups. ${ }^{6 b}$ The three 2,3,5,6-tetrachlorophenyl groups are twisted about $50^{\circ}$ to minimize the repulsion of the large chlorine atoms placed in ortho. This geometry prevents $\pi$ delocalization between the carbazolyl moiety and the phenyl ring and pointing that the radical lies almost exclusively over the tris-arylsubstituted carbon atom (with a computed spin density of 0.733 ).

Fig. 2 shows the $\mathrm{X}$-band EPR spectrum of radical adduct $\mathbf{1}$, that was recorded in $\mathrm{CH}_{2} \mathrm{Cl}_{2}$ solution $\left(10^{-3} \mathrm{M}\right)$ at $178 \pm 5 \mathrm{~K}$. The EPR spectrum recorded at $298 \pm 3 \mathrm{~K}$ is shown in Fig. $\mathrm{S} 1$ (ESI $\dagger$ ). ightly overlapped triplet $(1: 2: 1)(g=2.00255 \pm 0.00003$ $\Delta H_{\mathrm{pp}}=0.58 \mathrm{G}$ at $298 \mathrm{~K}$ and $0.37 \mathrm{G}$ at $\left.178 \mathrm{~K}\right)$ with an electron coupling to two para-hydrogens $(a=1.92 \mathrm{G})$ and a nitrogen $(a=$ $0.32 \mathrm{G})$. The coupling of the unpaired electron with the nitrogen nucleus is quite apparent in the spectrum at $178 \mathrm{~K}$ (Fig. 2b) due to the two slope changes appearing from the maximum to the minimum along each band. This fact supports the presence of a certain spin density on the nitrogen atom in spite of the extreme torsion (about $90^{\circ}$ ) the $\mathrm{C}-\mathrm{N}$ bond suffers because of the stereo effect released by the ortho chlorine atoms. The corresponding coupling values of the free electron with the central ${ }^{13} \mathrm{C}$ atom $(30.22 \mathrm{G}$ ), only emerging in the spectrum at $298 \mathrm{~K}$ (see
Fig. S1, ESI $\dagger$ ), with three neighboring ${ }^{13} \mathrm{C}$ atoms $(a=13.01 \mathrm{G})$, with the six ortho ${ }^{13} \mathrm{C}$ atoms $(a=10.47 \mathrm{G})$ and even with the three para ${ }^{13} \mathrm{C}$ atoms $(a=5.81 \mathrm{G})$ appear in the simulated spectrum at low temperature.

The optical properties of radical adduct 1 were evaluated by measuring its absorption and emission spectra in different solvents. The absorption spectra of $\mathbf{1}$ in $\mathrm{CH}_{2} \mathrm{Cl}_{2}$ and in DMF are displayed in Fig. 3. Table 1 lists the computed electronic transitions and oscillator strengths, obtained at the TD-UB3LYP/6$31+\mathrm{G}(2 \mathrm{df}, 2 \mathrm{p})$ level of theory for the optimized geometry calculated at the UB3LYP/6-31+G(2df,2p) level in both the mentioned solvents. Fig. 4 shows the calculated spectra using different solvents while Fig. 5 shows the most relevant topological features of the main orbitals involved in the computed electronic transitions.

The spectrum in $\mathrm{CH}_{2} \mathrm{Cl}_{2}$ showed three typical bands in the range of $\lambda 289-330 \mathrm{~nm}$, a strong band at $\lambda=378 \mathrm{~nm}$, a broad and weak multiplet at $\beta=480-560 \mathrm{~nm}$, and a weak broad absorption band centered at $\lambda=620 \mathrm{~nm}$. The three bands at $\lambda=$ 289, 318 and $330 \mathrm{~nm}$ have a close similarity with the bands observed in $\mathrm{NH}$-carbazole (see Fig. S2, ESI $\dagger$ ), which confirms the poor electronic coupling between the heterocycle and the phenyl ring, as suggested by the structure of the radical discussed above. Thus, each part of the molecule forms an isolated chromophore. As an example, the spectrum of radical adduct 1 in THF (Fig. S2, ESI $\dagger$ ) practically arises from the additional combination of the spectra of $\mathrm{NH}$-carbazole and b

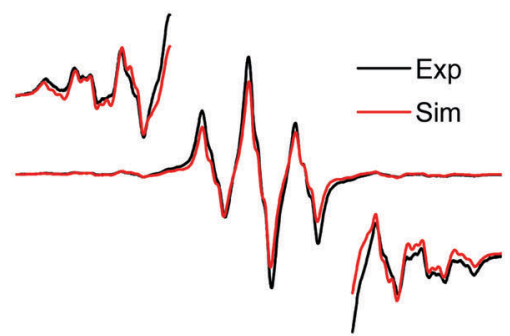

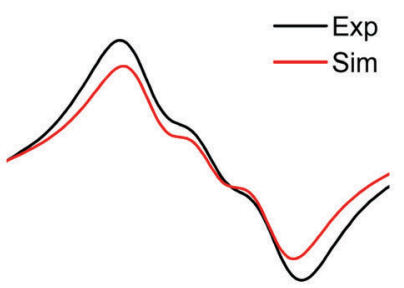

3367

3368

3369
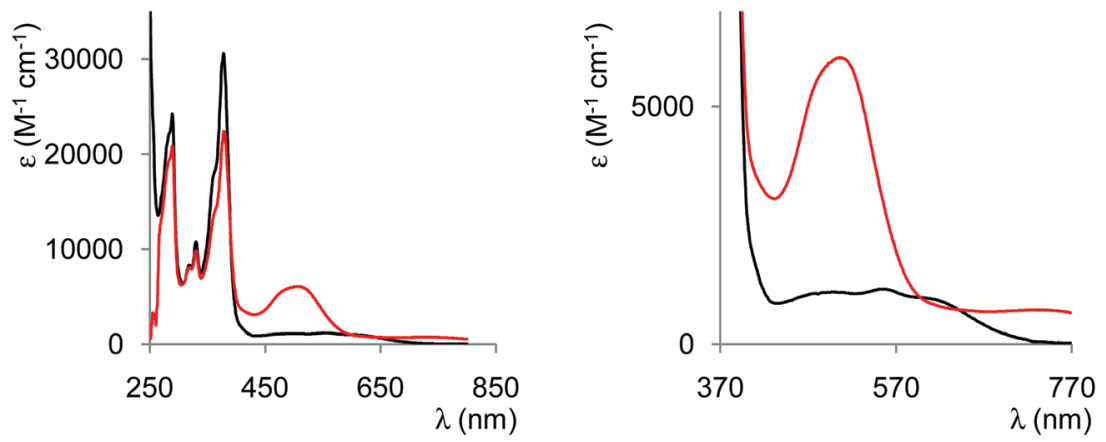

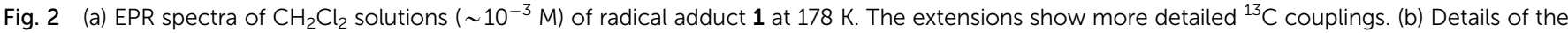
central band showing weak electron-nitrogen nucleus coupling

Fig. 3 UV-vis spectra of radical adduct 1 in $\mathrm{CH}_{2} \mathrm{Cl}_{2}$ (black) and DMF (red). Right: Details of the less energetic bands of the spectra. 

computed with $\mathrm{CH}_{2} \mathrm{Cl}_{2}$ and DMF solvents. The main transition and its electronic nature are also given ${ }^{a}$

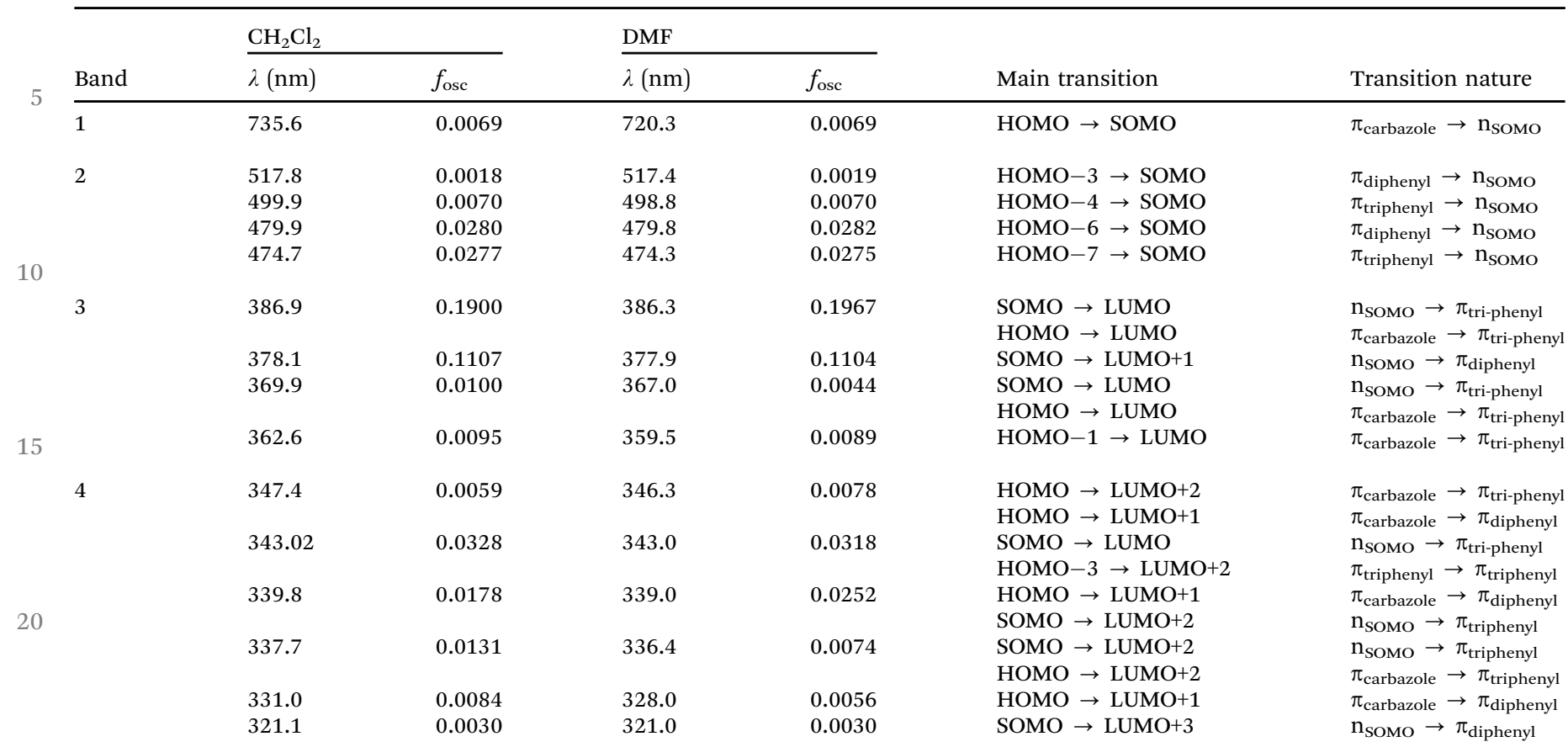

${ }^{a}$ Computed at the TD-B3LYP/6-31+G(2df,2p) level of theory.

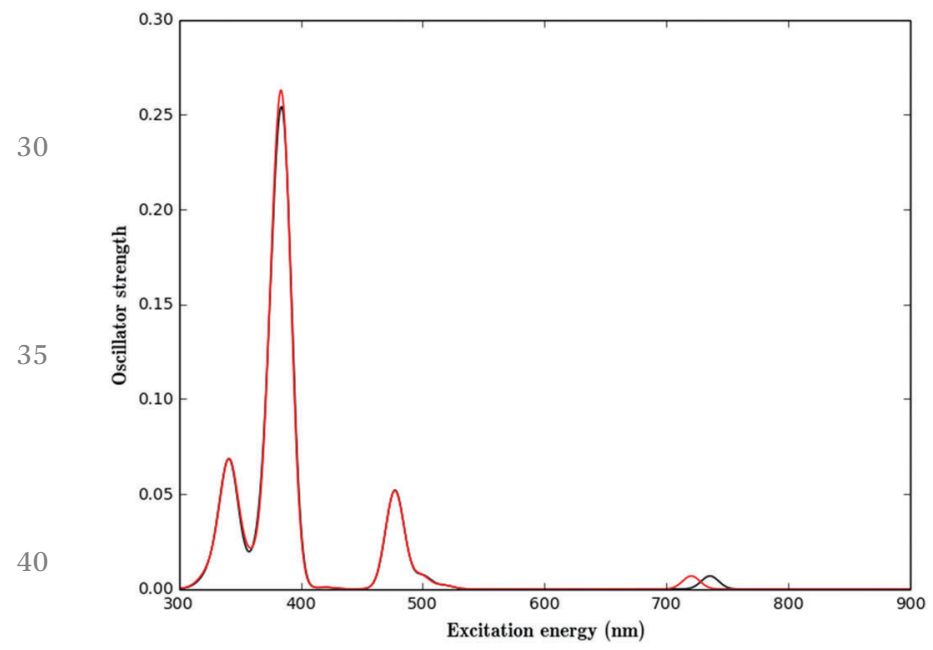

Fig. 4 Calculated electronic spectra of radical adduct 1 in $\mathrm{CH}_{2} \mathrm{Cl}_{2}$ (black) and DMF (red). They overlap in a great part of the spectra. We have used a Gaussian function to draw the calculated spectra, with an arbitrary sigma value of 100 .

the DTM radical, confirming again the lack of conjugation between both halves of the molecule, except for the presence of a very low intensity broad band in the less energetic region of the spectrum. Theoretical calculations have performed up to an excitation energy at $320 \mathrm{~nm}$, and the computed bands compare quite well with the experimental observations except for the less energetic one (Table 1 and Fig. 4). Band 4 (347-321 nm), involving up to six electronic transitions, has a strong component involving excitation from the $\pi$ system of the carbazolyl

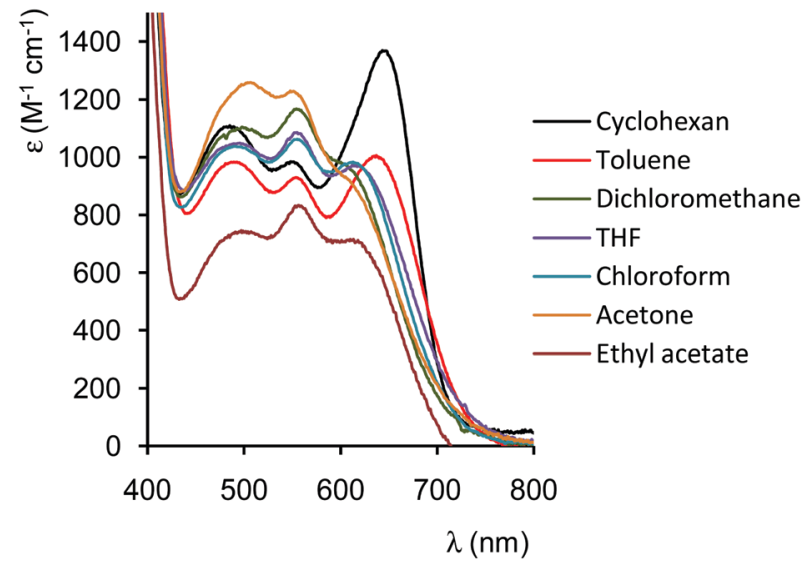

Fig. 5 Details of the absorptivities of the electronic spectra of 1 (400$800 \mathrm{~nm}$ ) in solvents of different polarities.

moiety to the anti-bonding $\pi^{*}$ orbitals of the phenyl groups. Moreover, the theoretical calculations also show that there is a strong contribution involving an excitation from the unpaired electron $\left(\mathrm{n}_{\text {SOMo }}\right)$ to the anti-bonding $\pi^{*}$ orbitals of the phenyl groups too.

The strongest absorption band in $\mathrm{CH}_{2} \mathrm{Cl}_{2}$ picked at $\lambda=$ $378 \mathrm{~nm}$ in very good agreement with the results of the theoretical calculations. It includes up to four electronic transitions, with $\lambda_{\max }$ at $384 \mathrm{~nm}$, and corresponds to excitations from the unpaired electron $\left(\mathrm{n}_{\text {SOMO }}\right)$ to the anti-bonding $\pi^{*}$ orbitals of the phenyl groups (see Fig. S3 (ESI $\dagger$ ) and Table 1). The broad and weak multiplet at $\lambda=480-560 \mathrm{~nm}$ is characteristic of the highly

1

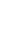

(1)


1 chlorinated triphenylmethyl radicals involving up to four electronic transitions, from the $\pi$ systems of the phenyl groups to the SOMO orbital. Finally, the lowest energy band appeared at $\lambda$ $=620 \mathrm{~nm}$ in $\mathrm{CH}_{2} \mathrm{Cl}_{2}$ and can be ascribed to an intramolecular charge transfer (ICT) from the carbazolyl moiety (HOMO orbital, with $\pi_{\text {nitrogen-carbazole }}$ character) to the acceptor trivalent carbon atom (SOMO). It is worth mentioning that theoretical calculations predict this electronic transition centered at a longer wavelength $(736 \mathrm{~nm})$; such a large error is expected due to the inability of the time dependent density functional (TDDF-UB3LYP) methods to adequately describe the electronic transitions involving charge transfer electronic states. ${ }^{11}$

The influence of environment polarity on the nature and energetic of the electronic transitions has been examined in solvents with different polarizabilities showing that the multiplet absorption $(\lambda=480-560 \mathrm{~nm})$ remains fairly insensitive to the solvent polarity while the ICT band exhibits solvatochromism (Fig. 5), with an hypsochromic effect on moving from non-polar to polar solvents (Table S1, ESI $\dagger$ ). This band clearly emerges as a maximum peak in non-polar solvents (cyclohexane and toluene), whereas it is displayed only as a shoulder in the longer wavelength region of the multiplet in polar solvents, such as acetone and ethyl acetate. This shift of the electronic transition to shorter wavelengths suggests a significant increase in the HOMO/LUMO gap with the polarity of the solvent.

It is worth mentioning that the different features observed in the absorption spectrum of $\mathbf{1}$ are recorded in DMF (dipole moment, 3.82 D) (Fig. 6). A new band of low intensity $(\lambda=$ $493 \mathrm{~nm}$ ) emerges from the most energetic region of the multiplet, which does not appear in solvents with low polarizability. At first glance this band can be tentatively explained assuming the coexistence in equilibrium of two different structures for 1 in DMF, namely the neutral and the zwitterionic structures resulting from a charge transfer of an electron from the nitrogen atom of the carbazolyl moiety to the trivalent carbon atom linking the three phenyl groups, as it was previously suggested in related compounds. ${ }^{12}$ Thus assigning this band to a single excitation from double occupied lone pair of the trivalent

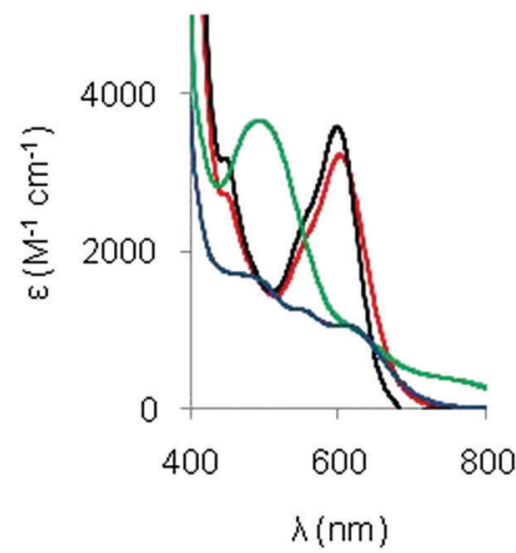

Fig. 6 Details of the visible spectra of $\mathrm{CzTTM}$ in $\mathrm{CHCl}_{3}$ (black) and DMF (red), and of 1 in $\mathrm{CHCl}_{3}$ (blue) and DMF (green). carbon atom. In order to explore this possibility, the electronic spectrum of the triphenylmethide anion $\left(\mathbf{1}^{-}\right)$, obtained by reduction of 1 in THF with TBAH, showed a very strong broad band at $\lambda \sim 510 \mathrm{~nm}$ (Fig. S4, ESI $\dagger$ ). In addition, the spectra of the optimized triphenylmethide anion at the B3LYP/6$31+\mathrm{G}(2 \mathrm{df}, 2 \mathrm{p})$ level of theory in $\mathrm{CH}_{2} \mathrm{Cl}_{2}$ and DMF solvents showed a very intense band at $\lambda=489 \mathrm{~nm}$ (Fig. S5, ESI $\dagger$ ), very close to the experimental value. These results seem to support the idea of a possible equilibrium between the neutral and zwitterionic forms of $\mathbf{1}$ in DMF but highly displaced towards the neutral species as the difference in intensities of the bands of the anion $(\lambda=493 \mathrm{~nm})$ and the radical $(\lambda=378 \mathrm{~nm})$ in the spectrum recorded in DMF is very large. On the other hand, the low intensity band at $\lambda=493 \mathrm{~nm}$ observed in DMF solution could also be assigned, from theoretical calculations (Table 1), to band 2 (involving $\pi_{\text {phenyl }} \rightarrow \mathrm{n}_{\text {somo }}$ transitions), although the intensity change observed for this band in different solvents is not well reproduced by the calculations.

Radical adduct 1 presents a completely different behavior from radical adduct czTTM (see Scheme 1) previously reported in the literature. ${ }^{6,7}$ In the visible range of the spectra $(\lambda=390-$ $700 \mathrm{~nm}$ ) of czTTM, solvatochromism has little effect on the polarity of the solvent, with the intramolecular charge transfer band arising at a value of $\lambda \sim 600 \mathrm{~nm}$ either in $\mathrm{CHCl}_{3}$ or in DMF (Fig. 6). This is a consequence of the weaker electronwithdrawing effect of TTM than that of DTM.

Radical adduct 1 was weakly emissive in non-polar solvents such as cyclohexane. When $\mathbf{1}$ is excited in cyclohexane solution $\left(\lambda_{\text {exc }}=450 \mathrm{~nm}\right)$, an emission peak $(\lambda=700 \mathrm{~nm})$ with a low quantum yield $(\Phi=0.018)$ appeared in the luminescence spectrum (Fig. S6, ESI $\dagger$ ). No luminescence was detected in polar solvents. This behavior is in agreement with the process of fluorescence quenching in donor-acceptor molecules, with the excess energy of the excited state being dissipated, especially in polar solvents, due to the strong interactions between the electron transfer nature of the excited state and the solvent. A different behavior is presented in $\operatorname{czTTM}(\Phi=0.53$ and 0.02 in cyclohexane and $\mathrm{CHCl}_{3}$, respectively), where the flexibility of the carbazolyl phenyl single bond allows a degree of coplanarity between the two parts of the molecule in the excited state, due to the absence of neighboring chlorines. The Stokes shift value, difference between maximum peaks of the lowest energy absorption band and the highest energy emission band, is attributed to the energy difference between the Franck-Condon and the stabilized excited states of $\mathbf{1}$. This difference is the result of geometry molecular relaxation and solvent reorganization in the excited state. The Stokes shift value is only moderate $\left(1218 \mathrm{~cm}^{-1}\right)$ in a cyclohexane solution of 1 .

The cyclic voltammogram of radical adduct 1 was recorded in $\mathrm{CH}_{2} \mathrm{Cl}_{2}$ solution $\left(\sim 10^{-3} \mathrm{M}\right)$ containing TBAP $(0.1 \mathrm{M})$ as the supporting electrolyte on platinum wire as the working electrode and $\mathrm{Ag} / \mathrm{AgCl}$ as the reference electrode. This showed an electrochemical amphoteric behavior with reduction and oxidation processes to anionic and cationic species, respectively. It exhibited a quasi-reversible redox pair $(\mathrm{O} / \mathrm{R})$ with a standard potential, $E^{\circ}=-0.12 \mathrm{~V}\left(E_{\mathrm{p}}^{\mathrm{a}}-E_{\mathrm{p}}^{\mathrm{c}}=126 \mathrm{mV}\right.$ at a scan rate, $0.1 \mathrm{~V}$ 


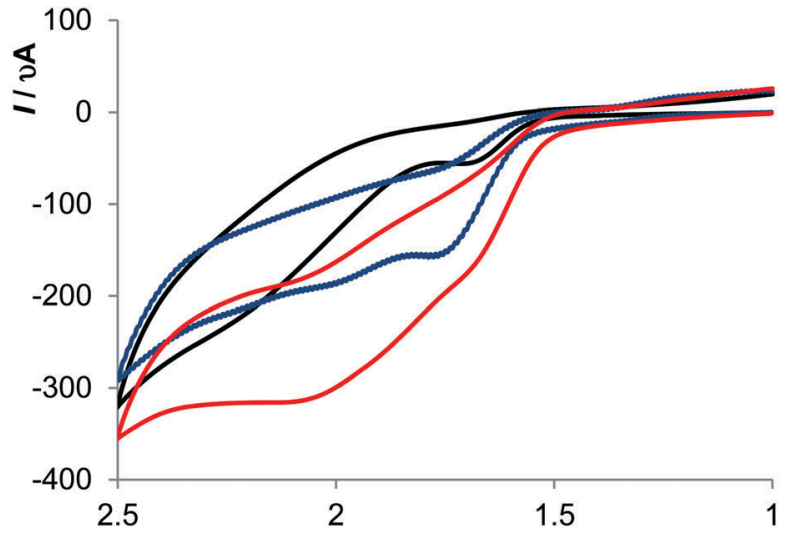

Fig. 7 Cyclic voltammograms for the oxidation of $\mathbf{1}$ (red), DTM (black) and $\mathrm{N}$-(pentachlorophenyl)carbazole (blue) in $\mathrm{CH}_{2} \mathrm{Cl}_{2}$ with $0.1 \mathrm{M}$ TBAP on Pt at $25^{\circ} \mathrm{C}$, at a scan rate of $0.1 \mathrm{~V} \mathrm{~s}^{-1}$. The initial and final potential was $1 \mathrm{~V}$; the inversion potential was $2.5 \mathrm{~V}$.

$\mathrm{s}^{-1}$ ), associated with the reduction process of $\mathbf{1}$, by addition of one electron to the SOMO so that the resulting system acquires a closed-shell electronic configuration (Fig. S7, ESI $\dagger$ ). This observed redox potential is very close to that of reduction of DTM $\left(E^{\circ}=-0.12 \mathrm{~V}\right)$, which suggests that reduction of 1 occurs in the trivalent carbon, independent of another redox moiety of the molecule. Furthermore, 1 displayed an irreversible oxidation peak overlapped with the background peak at $E_{\mathrm{p}}^{\mathrm{a}}=1.69 \mathrm{~V}$ at a scan rate, $0.1 \mathrm{~V} \mathrm{~s}^{-1}$, which practically coincides with the oxidation potential value of DTM $\left(E_{\mathrm{p}}^{\mathrm{a}}=1.70 \mathrm{~V}\right)$ and is slightly lower than the value of $N$-(pentachlorophenyl)carbazole $\left(E_{\mathrm{p}}^{\mathrm{a}}=\right.$ $1.78 \mathrm{~V}$ ) (Fig. 7). The oxidation peak of DTM as a maximum in the graph is relatively clean and overlapped with a multiple oxidation process at higher potentials. The first oxidation peak of $\mathrm{N}$-(pentachlorophenyl)carbazole, which corresponds to the loss of an electron and the generation of a radical cation, is also overlapped with a second peak emerging from subsequent multiple oxidations. The fact that the oxidation peaks of DTM and $\mathrm{N}$-(pentachlorophenyl)carbazole are similar, and both

40 redox centers are electronically decoupled in the molecule of $\mathbf{1}$, suggests that the oxidation peak insinuated in the graph of $\mathbf{1}$ corresponds most likely to consecutive loss of two electrons, one from each moiety. Radical adduct czTTM is more readily oxidizable $\left(E_{\mathrm{p}}^{\mathrm{a}}=1.075 \mathrm{~V} \text { at } 0.1 \mathrm{~V} \mathrm{~s}^{-1} \text {, vs. } \mathrm{Ag} / \mathrm{AgCl}\right)^{7}$ than 1. The presence of six additional chlorine atoms in the meta-position to the trivalent carbon in $\mathbf{1}$ hinders significantly the tendency toward oxidation of $\mathbf{1}$. The irreversible electrochemical oxidation process of $\mathbf{1}$ confirms the instability of the resulting species $\mathbf{1}^{+}$. Chemical oxidation of $\mathbf{1}$ by means of an excess of elemental analysis corresponded to the molecular formula $4\left(\mathbf{1}^{+} \mathbf{S b C l}_{\mathbf{6}}{ }^{-}\right) \cdot \mathbf{1}\left(\mathbf{S b}_{\mathbf{2}} \mathbf{O}_{3}\right)$ with a moderate yield. The EPR spectrum in solid yielded a weak and broad band $(g=2.0029 \pm 0.0002$; $\left.\Delta H_{\mathrm{pp}}=5.89 \mathrm{G}\right)$. However, when trying to run a UV-vis spectrum in solution, the salt was very unstable in any solvent. It is well known that positions 3, 6, and 9 in $\mathrm{NH}$-carbazole are extremely reactive; if these sites are not blocked by inert substituents, the oxidized species reacts rapidly via coupling-deprotonation. ${ }^{13}$ To estimate the electron affinity (EA) and the ionization potential (IP) from the measured electrochemical potentials, it is necessary to correlate the potential onsets with the vacuum level. The onset values are estimated from the intersection of the two tangents drawn at the increasing oxidation or reduction current and the background current in the voltammograms. As the Ag/ $\mathrm{AgCl}$ electrode has an energy of $4.4 \mathrm{eV}$ at the zero vacuum level, the EA of 1 is $4.37 \mathrm{eV}\left(E_{\text {onset }}^{\mathrm{c}}+4.4\right)$, and the IP of 1 is $5.92 \mathrm{eV}$ $\left(E_{\text {onset }}^{\mathrm{a}}+4.4\right)$, with the band-gap (difference between IP and EA) being $1.55 \mathrm{eV}$. The vertical EA and IP values have also been estimated by performing single point energy calculations at the LPNO-CCSD (local pair natural orbital coupled cluster single and double) level, ${ }^{14}$ and employing the cc-pVTZ basis set at the B3LYP optimized geometry of adduct 1, with the computed values being 5.01 and $5.43 \mathrm{eV}$ in quite good agreement with the experimental values.

As pointed out in ref. 15, while in molecules bearing an even number of electrons IP and EA are used to estimate the HOMO and LUMO energy levels; in the case of the neutral radicals it must be considered that the energy involved in the oxidation and the reduction processes is used to remove or attach an electron in the same semi-occupied orbital. Oxidizing a molecule means supplying the necessary energy to overcome the binding energy of the electron that is removed. Since this electron is located in the highest energy level, the energy required to promote it to infinity, IP, is taken as the HOMO energy. Similarly, the EA is the energy released when an electron is attached to a neutral molecule, which is taken as the LUMO energy, that is, the energy of the MO where the electron remains. In the case of the neutral radicals, the removed electron comes from the SOMO and the attached electron ends up in the SOMO. Therefore, it could be expected that the IP and the EA had the same value corresponding to the SOMO energy. However, in the reduction process, the new electron is not attached to an empty MO, but to a half-filled one. Thus, some repulsion energy must be overcome and the energy released in the reduction process (EA) is lower than that in the oxidation process (IP). ${ }^{15}$

\section{Conclusions}

A direct radical-radical coupling of $\mathrm{N} H$-carbazole with a persistent radical, DTM, has been accomplished in the presence of a base. The transient carbazolyl radical derived from the $\mathrm{NH}$ carbazole via electron transfer reaction with DTM in the presence of $\mathrm{Cs}_{2} \mathrm{CO}_{3}$ readily combines with another molecule of DTM to give 1 . Thus, a $\mathrm{C}\left(\mathrm{sp}^{2}\right)-\mathrm{H}$ bond can be transformed into the $\mathrm{C}\left(\mathrm{sp}^{2}\right)-\mathrm{N}$ bond through the radical-radical crosscoupling process. This radical adduct is formed by an electron-donor moiety, the carbazolyl ring, and an electronwithdrawing part, the polychlorotriphenylmethyl radical. Theoretical calculations predict that the tetrachlorophenyl bridge moiety lies perpendicular to the carbazolyl group to minimize 

the three phenyl rings are also twisted $\left(\sim 50^{\circ}\right)$ around their bond with the central carbon atom. In spite of the drastic reduction of the conjugation due to the lack of molecular coplanarity, the EPR spectrum of radical adduct 1 in diluted solution at low temperature exhibits a small coupling between the electronic spin, located mainly in the central $\mathrm{sp}^{2}$ carbon atom $(30.22 \mathrm{G})$, and the carbazolyl nitrogen $(0.32 \mathrm{G})$.

The absorption spectrum of $\mathbf{1}$ is a combination of the 10 spectra of radicals of the PTM (perchlorotriphenylmethyl) series and the $\mathrm{NH}$-carbazole, confirming the lack of conjugation between both moieties. However, it is worth mentioning the presence of a new weak charge transfer band from the carbazolyl group to the central $\mathrm{sp}^{2}$ carbon atom. This is the less mism in organic solvents showing a hypsochromic shift with the solvent polarity. The new weak band shown in the spectrum of 1 in DMF at a much shorter wavelength $(493 \mathrm{~nm})$ is tentatively attributed to the zwitterionic structure of the moleatom to the trivalent carbon atom. Currently, this phenomenon is being studied in a similar radical adduct, by increasing the electron-donating power of the carbazolyl substituent and, in this way, increasing the stability of the zwitterionic species.

Only a very weak emission was observed in $\mathbf{1}$ in cyclohexane and no emission was detected in polar solvents owing to the electron transfer nature of the excited state. One of the main differences in $\mathbf{1}$ in relation to czTTM (see Scheme 1) is the different behavior of the excited states. Thus, while czTTM is fluorescent $\left(\varphi=0.53\right.$ in cyclohexane, $\varphi=0.02$ in $\left.\mathrm{CHCl}_{3}\right),{ }^{6 a}$ radical adduct 1 hardly shows luminescence in cyclohexane $(\varphi=0.02)$. This difference in the way of dissipating the excess of energy of the excited states may be associated with their different geometries. The geometry of both states is controlled by the phenylic hydrogen or chlorine atoms ortho to the carbazole nitrogen. The stereo effect of the chlorine atoms in $\mathbf{1}$ causes a great repulsion to the planarity between phenyl and carbazole in $\mathbf{1}$.

Electrochemically, $\mathbf{1}$ shows a quasi-reversible process associated with the reduction of $\mathbf{1}$ to the stable diamagnetic anion, and an irreversible oxidation process associated with the consecutive loss of electrons from the carbazolyl moiety and the central $\mathrm{sp}^{2}$ carbon atom. Theoretical values of the IP and EA are in quite good agreement with the experimental values estimated from the oxidation and reduction potentials, respectively.

\section{Material and methods}

\section{General procedures}

IR spectra were recorded with an FT-IR spectrophotometer, electronic spectra with a single cell spectrophotometer and the X-band EPR spectra at $\mathrm{rt}$ and $180 \mathrm{~K}$ with an EMX-Plus 10/12 spectrometer. HRMS was performed in an LC/MSD-TOF apparatus by means of the electrospray (ESI-MS) technique. Cyclic voltammograms were recorded with an Autolab PGSTAT30 instrument using a conventional three-electrode cell.
Reaction of tris(2,3,5,6-tetrachlorophenyl)methyl radical (DTM) with $\mathrm{NH}$-carbazole in DMF

A mixture of $\mathrm{NH}$-carbazole $(0.500 \mathrm{mg} ; 3.0 \mathrm{mmol})$, DTM $(0.500$ $\mathrm{mg} ; 0.8 \mathrm{mmol})$, anhydrous $\mathrm{Cs}_{2} \mathrm{CO}_{3}(0.500 \mathrm{~g} ; 1.5 \mathrm{mmol})$, and DMF $(10 \mathrm{~mL})$ was stirred at reflux $(2 \mathrm{~h})$ in an inert atmosphere and in the dark. The resulting mixture was poured into an excess of diluted aqueous $\mathrm{HCl}$ acid, and the precipitate was filtered off. The solid was chromatographed in silica gel with hexane and with hexane/ $\mathrm{CHCl}_{3}(2: 1)$ to give tris(2,3,5,6-tetrachlorophenyl)methane $(0.222 \mathrm{~g} ; 44 \%)$ and [4-( $N$-carbazolyl)2,3,5,6-tetrachlorophenyl]bis(2,3,5,6-tetrachlorophenyl)methane (1H) $(0.145 \mathrm{~g} ; 22 \%) ;{ }^{1} \mathrm{H}$ NMR $\left(400 \mathrm{MHz}, \mathrm{CDCl}_{3}\right)$ (Fig. S8, ESI $\dagger$ ) $\delta$ $8.16(\mathrm{~d}, 2 \mathrm{H}, J=8 \mathrm{~Hz}), 7.71(\mathrm{~s}, 1 \mathrm{H}), 7.72(\mathrm{~s}, 1 \mathrm{H}), 7.42-7.47(\mathrm{~m}, 2 \mathrm{H})$, $7.327 .36(\mathrm{~m}, 2 \mathrm{H}), 7.16(\mathrm{~s}, 1 \mathrm{H}), 6.95(\mathrm{~d}, 1 \mathrm{H}, J=8 \mathrm{~Hz}), 6.92(\mathrm{~d}, 1 \mathrm{H}, J$ $=8 \mathrm{~Hz})$. (ESI) HRMS calcd for $\mathrm{C}_{31} \mathrm{H}_{10}{ }^{35} \mathrm{Cl}_{12} \mathrm{~N}(\mathrm{M}-\mathrm{H})^{\bullet}$ 815.7081, found $\mathrm{m} / \mathrm{z} 815.7061$.

Synthesis of the [4-( $N$-carbazolyl)-2,3,5,6-tetrachlorophenyl]bis(2,3,5,6-tetrachlorophenyl)methyl radical (1)

Tetrabutylammonium hydroxide (TBAH) $(1.0 \mathrm{M} ; 0.6 \mathrm{~mL})$ was added to a solution of [4-( $N$-carbazolyl)-2,3,5,6-tetrachlorophenyl]bis(2,3,5,6-tetrachlorophenyl)methane $(0.372 \mathrm{~g} ; 0.453 \mathrm{mmol})$ in THF $(15 \mathrm{~mL})$ and the mixture was stirred $(2 \mathrm{~h})$ at $0{ }^{\circ} \mathrm{C}(4 \mathrm{~h})$. Iodine $(0.700 \mathrm{~g})$ in THF $(10 \mathrm{~mL})$ was added to the reaction mixture and stirred in the dark under an inert atmosphere $(\mathrm{Ar})(24 \mathrm{~h})$. The mixture was poured into an excess of aqueous solution of sodium hydrogen sulphite, and the precipitate was filtered, washed several times with water and dried to give 1 (0.350 g; 95\%); IR (KBr) 1658 (w), $1626(\mathrm{w}), 1600(\mathrm{w}), 1532(\mathrm{~m}), 1492(\mathrm{~m}), 1479(\mathrm{~m}), 1453(\mathrm{~s}), 1374$ (s), $1332(\mathrm{~s}), 1313(\mathrm{~s}), 1246(\mathrm{~m}), 1228(\mathrm{~s}), 1163(\mathrm{~m}), 1148(\mathrm{w}), 1012$ (m), $985(\mathrm{~m}), 856(\mathrm{~m}), 748(\mathrm{~s}), 737(\mathrm{~m}), 704(\mathrm{~m}), 687(\mathrm{~m}), 660(\mathrm{w})$ $\mathrm{cm}^{-1}$; (ESI) HRMS calcd for $\mathrm{C}_{31} \mathrm{H}_{9}{ }^{35} \mathrm{Cl}_{12} \mathrm{~N}$ 815.7081, found $\mathrm{m} / \mathrm{z}$ 815.7071.

\section{Synthesis of $N$-pentachlorobenzenecarbazole}

A solution of $\mathrm{NH}$-carbazole $(0.300 \mathrm{~g} ; 1.79 \mathrm{mmol})$ in DMF $(15 \mathrm{~mL})$ is slowly $(20 \mathrm{~min})$ added to a solution of perchlorobenzene $(0.500 \mathrm{~g} ; 1.76 \mathrm{mmol})$ in DMF $(20 \mathrm{~mL})$ at $130{ }^{\circ} \mathrm{C}$ in an inert (Ar) atmosphere, and the mixture was left further $(5 \mathrm{~h})$, and poured into an excess of diluted aqueous $\mathrm{HCl}$ acid, and the precipitate was filtered off. The solid was chromatographed in silica gel with hexane/ $\mathrm{CHCl}_{3}(2: 1)$ to give the recovered starting material ( $0.247 \mathrm{~g} ; 49 \%), \mathrm{N}$-pentachlorobenzenecarbazole ( 0.071 g; $19 \%$ in relation to the reacted perchlorobenzene); ${ }^{1} \mathrm{H}$ NMR $\left(400 \mathrm{MHz}, \mathrm{CDCl}_{3}\right)$ (Fig. S9, ESI $\left.\dagger\right) \delta 8.16(\mathrm{~d}, 2 \mathrm{H}, J=8 \mathrm{~Hz}), 7.43$ $\left(\mathrm{dd}, 2 \mathrm{H}, J=J^{\prime}=8 \mathrm{~Hz}\right), 7.34\left(\mathrm{dd}, 2 \mathrm{H}, J=J^{\prime}=8 \mathrm{~Hz}\right), 6.965(\mathrm{~d}, 2 \mathrm{H}, J=$ $8 \mathrm{~Hz}$ ). (ESI) HRMS calcd for $\mathrm{C}_{18} \mathrm{H}_{9} \mathrm{Cl}_{5} \mathrm{~N}(\mathrm{M}+\mathrm{H})^{+} 415.9144$, found $m / z 415.9139$.

\section{Synthesis of the salt $\mathbf{1}^{+} \mathbf{S b C l}_{6}{ }^{-}$}

To a solution of 1 ( $0.080 \mathrm{~g} ; 0.097 \mathrm{mmol})$ in anhydrous $\mathrm{CCl}_{4}(25$ $\mathrm{mL})$ under an anhydrous atmosphere, $\operatorname{SbCl}_{5}(2 \mathrm{~mL})$ was added. The reaction mixture was stirred at $\mathrm{rt}(4 \mathrm{~h})$ and the resulting precipitate was filtered off and washed with $\mathrm{CCl}_{4}$, maintaining an anhydrous atmosphere with infrared light. The solid $(0.053$ 
$1 \mathrm{mg}$ ) was characterized as $\mathbf{4}$ Salt: $\mathbf{1} \mathbf{S b}_{2} \mathbf{O}_{3}$. Anal. calcd for $\mathrm{C}_{124} \mathrm{H}_{40} \mathrm{C}_{172} \mathrm{~N}_{4} \mathrm{O}_{3} \mathrm{Sb}_{6}$ : C, 30.3; H, 0.82; Cl, 51.9; N, 1.1. Found: C, 30.3; H, 0.47; Cl, 50.7; N, 1.06 .

\section{Theoretical calculations}

The search for the stationary points has been done by employing the density functional theory (DFT) with the B3LYP function, ${ }^{16}$ using the $6-31+\mathrm{G}(2 \mathrm{df}, 2 \mathrm{p})$ basis set, ${ }^{17}$ whereas the electronic spectra have been computed in the framework of Time-Dependent Density Functional theory, ${ }^{18}$ with the B3LYP functional employing the same basis. All doublet electronic states have been investigated using the unrestricted B3LYP (UB3LYP) approach. The ionization potential and electronic affinity have been estimated carrying out single point energy calculations at the LPNO-CCSD (local pair natural orbital coupled cluster single and double) level, ${ }^{14}$ using the cc-pVTZ basis set. ${ }^{19}$ Along this work we have employed the Gaussian $09^{20}$ program for all DFT calculations, the ORCA ${ }^{21}$ program for the LPNO-CCSD calculations, and the Molden program $^{22}$ for visualizing the electronic features. The optimized Cartesian coordinates in $\AA$ and the absolute energy in hartrees of radical adduct 1 obtained at the UB3LYP/6-31+G(2df,2p) level of theory are displayed in Table S2 (ESI $\dagger$ ).

\section{Acknowledgements}

Financial support for this research from the Ministerio de Economía y Competitividad (MINECO, Spain) through projects CTQ2015-65770-P (MINECO/FEDER) and AGL2013-49079-C2-2$\mathrm{R}$ is gratefully acknowledged. We also thank the EPR service of the Advanced Research Institute of Catalunya (CSIC) (Spain) for recording the EPR spectra. J. A. thanks the Spanish Secretaria de Estado de Investigación, Desarrollo e Innovación (CTQ201459768-P), and the Generalitat de Catalunya (Grant 2014SGR139). We also acknowledge the Consorci de Serveis Universitaris de Catalunya (CSUC) for providing computational resources.

\section{References}

1 (a) J. F. Ambrose and R. F. Nelson, J. Electrochem. Soc., 1968, 115, 1159-1164; (b) D. R. Prudhomme, Z. Wang and C. J. Rizzo, J. Org. Chem., 1997, 62, 8257-8260; (c) Z. Gomurashvili, Y. Hua and J. V. Crivello, Macromol. Chem. Phys., 2001, 202, 2133-2141; (d) M. Sangermano, G. Malucelli, A. Priola, S. Lengvinaite, J. Simokaitiene and J. V. Grazulevicius, Eur. Polym. J., 2005, 41, 475-480; (e) S.-K. Chiu, Y.-C. Chung, G.-S. Liou and Y. O. Su, J. Chin. Chem. Soc., 2012, 59, 1-7.

2 (a) I. B. Berlman, Handbook of Fluorescence Spectra of Aromatic Molecules, Academic Press, New York, 1971, p. 205; (b) J. C. Mastrangelo, B. M. Conger, S. H. Chen and A. BashirHashemi, Chem. Mater., 1997, 9, 227-232; (c) B. M. Conger, D. Katsis, J. C. Mastrangelo and S. H. Chen, J. Phys. Chem. A, 1998, 102, 9213-9218; (d) M. C. Castex, C. Olivero, G. Pichler, D. Ades, E. Cloutet and A. Siove, Synth. Met., 2001, 122, 59-61; (e) J. V. Grazulevicius, P. Strohriegl, J. Pielichowski and K. Pielichowski, Prog. Polym. Sci., 2003, 28, 1297-1353; $(f)$ K. Parimal, K. R. Justin Thomas, T. L. Jiann, Y. T. Tao and C. H. Chien, Adv. Funct. Mater., 2003, 13, 445-452; $(g)$ B. Akira, O. Ken, K. Wolfgang and C. A. Rigoberto, J. Phys. Chem. B, 2004, 108, 18949-18955.

3 (a) D. B. Romero, M. Schaer, M. Leclerc, D. Adès, A. Siove and L. Zuppiroli, Synth. Met., 1996, 80, 271-277; (b) K. R. Justin Thomas, J. T. Lin, Y.-T. Tao and C.-W. Ko, J. Am. Chem. Soc., 2001, 123, 9404-9411; (c) A. van Dijken, J. J. A. M. Bastiaansen, N. M. M. Kiggen, B. M. W. Langeveld, C. Rothe, A. Monkman, I. Bach, P. Stössel and K. Brunner, J. Am. Chem. Soc., 2004, 126, 7718-7727; (d) K. R. Justin Thomas, M. Velusamy, J. T. Lin, Y. T. Tao and C. H. Chuen, Adv. Funct. Mater., 2004, 14, 387-392; (e) M. Reig, G. Bubniene, W. Cambarau, V. Jankauskas, V. Getautis, E. Palomares, E. Martínez-Ferrero and D. Velasco, RSC $A d v$., 2016, 6, 9247-9253; $(f)$ M. Reig, C. Gozalvez, R. Bujaldon, G. Bagdziunas, K. Ivaniuk, N. Kostiv, D. Volyniuk, J. V. Grazulevicius and D. Velasco, Dyes Pigm., 2017, 137, 24-35.

4 M. Martinez-Palau, E. Perea, F. López-Calahorra and D. Velasco, Lett. Org. Chem., 2004, 1, 231-237.

5 (a) G. Mann, J. F. Hartwig, M. S. Driver and C. FernándezRivas, J. Am. Chem. Soc., 1998, 120, 827-828; (b) M. Watanabe, M. Nishiyama, T. Yamamoto and Y. Koie, Tetrahedron Lett., 2000, 41, 481-483.

6 (a) V. Gamero, D. Velasco, S. Latorre, F. López-Calahorra, E. Brillas and L. Juliá, Tetrahedron Lett., 2006, 47, 2305-2309; (b) L. Fajarí, R. Papoular, M. Reig, E. Brillas, J. L. Jorda, O. Vallcorba, J. Rius, D. Velasco and L. Juliá, J. Org. Chem., 2014, 79, 1771-1777.

7 S. Castellanos, D. Velasco, F. López-Calahorra, E. Brillas and L. Julia, J. Org. Chem., 2008, 73, 3759-3767.

8 M. López, D. Velasco, F. López-Calahorra and L. Juliá, Tetrahedron Lett., 2008, 49, 5196-5199.

9 (a) S. Castellanos, V. Gaidelis, V. Jankauskas, J. V. Grazulevicius, E. Brillas, F. López-Calahorra, L. Juliá and D. Velasco, Chem. Commun., 2010, 46, 5130-5132; (b) M. Reig, C. Gozalvez, V. Jankauskas, V. Gaidelis, J. V. Grazulevicius, L. Fajarí, L. Julià and D. Velasco, Chem. - Eur. J., 2016, 22, 18551-18558.

10 For a review of these exciting reactions, see: H. Fischer, Chem. Rev., 2001, 101, 3581-3610.

11 (a) A. Dreuw and M. Head-Gordon, Chem. Rev., 2005, 105, 4009-4037; (b) C. Adamo and Jacquemin, Chem. Soc. Rev., 2013, 42, 845-856.

12 M. Souto, M. V. Solano, M. Jensen, D. Bendixen, F. Delchiaro, A. Girlando, A. Painelli, J. O. Jeppesen, C. Rovira, I. Ratera and J. Veciana, Chem. - Eur. J., 2015, 21, 8816-8825.

13 J. F. Ambrose, L. L. Carpenter and R. F. Nelson, J. Electrochem. Soc., 1975, 122, 876-894.

14 D. G. Liakos and F. Neese, J. Chem. Theory Comput., 2015, 11, 4054-4063.

15 S. Castellanos, Doctoral thesis, University of Barcelona, Spain, 2010. 
116 A. D. Becke, J. Chem. Phys., 1993, 98, 5648-5652.

17 (a) M. J. Frisch, J. A. Pople and J. S. Binkley, J. Chem. Phys., 1984, 80, 3265-3269; (b) W. J. Hehre, L. Radom, P. v. R. Schleyer and J. A. Pople, Ab Initio Molecular Orbital Theory, John Wiley, New York, 1986, pp. 86-87.

18 F. Trani, G. Scalmani, G. Zheng, I. Carnimeo, M. J. Frisch and V. Barone, J. Chem. Theory Comput., 2011, 7, 3304-3313.

19 (a) T. H. J. Dunning, J. Chem. Phys., 1989, 90, 1007-1023; (b) R. A. Kendall, T. H. Dunning and R. J. Harrison, J. Chem. Phys., 1992, 96, 6796-6806.

20 M. J. Frisch, G. W. Trucks, H. B. Schlegel, G. E. Scuseria, M. A. Robb, J. R. Cheeseman, G. Scalmani, V. Barone, B. Mennucci, G. A. Petersson, H. Nakatsuji, M. Caricato, X. Li, H. P. Hratchian, A. F. Izmaylov, J. Bloino, G. Zheng, J. L. Sonnenberg, M. Hada, M. Ehara, K. Toyota, R. Fukuda, J. Hasegawa, M. Ishida, T. Nakajima, Y. Honda, O. Kitao,
H. Nakai, T. Vreven, J. A. Montgomery Jr., J. E. Peralta, F. Ogliaro, M. J. Bearpark, J. Heyd, E. N. Brothers, K. N. Kudin, V. N. Staroverov, R. Kobayashi, J. Normand, K. Raghavachari, A. P. Rendell, J. C. Burant, S. S. Iyengar, J. Tomasi, M. Cossi, N. Rega, N. J. Millam, M. Klene, J. E. Knox, J. B. Cross, V. Bakken, C. Adamo, J. Jaramillo, R. Gomperts, R. E. Stratmann, O. Yazyev, A. J. Austin, R. Cammi, C. Pomelli, J. W. Ochterski, R. L. Martin, K. Morokuma, V. G. Zakrzewski, G. A. Voth, P. Salvador, J. J. Dannenberg, S. Dapprich, A. D. Daniels, Ö. Farkas, J. B. Foresman, J. V. Ortiz, J. Cioslowski and D. J. Fox, Gaussian, Inc., Wallingford, CT, USA, 2009.

21 F. Neese, Wiley Interdiscip. Rev.: Comput. Mol. Sci., 2012, 2 , 73-78.

22 G. Shaftenaar and J. H. Noordik, J. Comput.-Aided Mol. Des., 15 2000, 14, 123-134. 